\title{
The effect of ambient air pollution on exhaled nitric oxide in the Children's Health Study
}

\author{
K. Berhane*, Y. Zhang*, W.S. Linn*, E.B. Rappaport*, T.M. Bastain*, M.T. Salam*, \\ T. Islam*, F. Lurmann" ${ }^{\#}$ and F.D. Gilliland*
}

ABSTRACT: We assessed the effect of daily variations in ambient air pollutants on exhaled nitric oxide fraction ( $F$ eNO) using data from a cohort of school children with large differences in air pollutant exposures from the Children's Health Study.

Based on a cohort of 2,240 school children from 13 Southern Californian communities, cumulative lagged average regression models were fitted to determine the association between FeNO and ambient air pollution levels from central site monitors with lags of up to $\mathbf{3 0}$ days prior to FeNO testing.

Daily 24-h cumulative lagged averages of particles with a $50 \%$ cut-off aerodynamic diameter of $2.5 \mu \mathrm{m}$ (PM2.5; over 1-8 days) and particles with a 50\% cut-off aerodynamic diameter of $10 \mu \mathrm{m}$ (PM10; over 1-7 days), as well as 10:00-18:00 h cumulative lagged average of $\mathrm{O}_{3}$ (over 1-23 days) were significantly associated with $17.42 \%(p<0.01), 9.25 \%(p<0.05)$ and $14.25 \%(p<0.01)$ higher FeNO levels over the interquartile range of $7.5 \mu \mathrm{g} \cdot \mathrm{m}^{-3}, 12.97 \mu \mathrm{g} \cdot \mathrm{m}^{-3}$ and $15.42 \mathrm{ppb}$, respectively. The effects of PM2.5, $\mathrm{PM}_{10}$ and $\mathrm{O}_{3}$ were higher in the warm season. The particulate matter effects were robust to adjustments for effects of $\mathrm{O}_{3}$ and temperature and did not vary by asthma or allergy status.

In summary, short-term increases in $\mathrm{PM}_{2.5}, \mathrm{PM}_{10}$ and $\mathrm{O}_{3}$ were associated with airway inflammation independent of asthma and allergy status, with PM10 effects significantly higher in the warm season.

KEYWORDS: Airway inflammation, air pollution, children's respiratory health, environmental epidemiology, exhaled nitric oxide

everal studies have shown that exposure to ambient air pollution at levels below the limits set by current regulatory standards are associated with significant adverse effects on children's respiratory health. Among a spectrum of adverse effects, ambient air pollution has been associated with deficits in lung growth $[1,2]$, increases in bronchitic symptoms [3] and development and/or exacerbation of asthma [4-7]. These results demonstrated that long-term exposure to ambient air pollution significantly impairs children's respiratory health, potentially leading to irreversible health consequences that may lead to premature morbidity and mortality later in life.

It is important to understand the contribution of air pollutants to the underlying pathophysiological mechanisms for these observed effects of air pollution in order to optimise interventions and regulatory policies designed to protect the most susceptible children. One mechanism that may play an important role is airway inflammation. In the past, it was not practically feasible to study airway inflammation directly in large populationbased prospective studies. The exhaled nitric oxide fraction $(\mathrm{FeNO})$ is a promising marker of important aspects of airway inflammation that has been developed and validated in the past decade $[8,9]$. Measurement of FeNO allows the assessment of inflammation in large epidemiological studies designed to identify populations that may be at increased risk for adverse health outcomes [10, 11].

In this study, we assessed the hypothesis that current levels of ambient air pollutants (including

This article has supplementary data available from www.erj.ersjournals.com

AFFILIATIONS

*University of Southern California, Los Angeles, and ${ }^{\text {\#S} S o n o m a ~ T e c h n o l o g y ~ I n c ., ~ P e t a l u m a, ~}$ CA, USA

CORRESPONDENCE

K. Berhane

Dept of Preventive Medicine, Keck

School of Medicine

University of Southern California

1540 Alcazar Street

CHP-220

Los Angeles

CA 90089-9011

USA

E-mail: kiros@usc.edu

Received:

May 252010

Accepted after revision:

Sept 152010

First published online:

Oct 142010 
particles with a 50\% cut-off aerodynamic diameter of 2.5 and $10 \mu \mathrm{m}$ (PM2.5 and PM10, respectively), $\mathrm{NO}_{2}$ and $\mathrm{O}_{3}$ ) are associated with airway inflammation in children as measured by FeNO. We investigated this hypothesis as part of the Southern California Children's Health Study (CHS), an ongoing prospective cohort study of environmental and genetic determinants of respiratory health in Southern Californian children $[7,12,13]$.

\section{METHODS}

\section{Study design and subjects}

Details on the design, site selection, subject recruitment and assessment of health effects are reported elsewhere [7]. Briefly, a cohort of 5,093 children from 13 communities in Southern California was enrolled in 2002-2003 from kindergarten and first grade classrooms (aged 5-7 yrs). At baseline and each subsequent year of follow-up, parents completed a written questionnaire. Informed assent was sought from each child, and informed consent from a parent or guardian. The protocol was approved by the University of Southern California Institutional Review Board.

Measurement of FeNO was performed at schools during the 2004-2005 school year using the offline technique according to the American Thoracic Society guidelines [8,9]. Details of the FeNO collection and quality-control approaches have been reported previously $[14,15]$. In a sub-sample $(n=361)$ for whom both off- and online $\left(50 \mathrm{~mL} \cdot \mathrm{s}^{-1}\right.$ flow) FeNO measurement techniques were used, online FeNO levels were reliably predicted (model adjusted $\mathrm{R}^{2}=0.94$ ) using a statistical model that incorporated offline FeNO, ambient $\mathrm{NO}$ and lag time between time of collection and FeNO measurement [14]. In the present analysis, predicted online FeNO data obtained from that model were used. Among the 3,544 children available in year 3 of the study, FeNO was measured in 2,792 subjects. We excluded children who did not have technically acceptable FeNO measurement $(n=82)$, and those from Lake Arrowhead due to lack of measurements of particulate matter $(n=209)$. In addition, we excluded 261 subjects because they reported use of inhaled corticosteroids $(n=51)$ or gave no information on their use of medication $(n=210)$. Therefore, the final analysis data set included 2,240 subjects.

Air pollution data were obtained from central monitoring sites in each study community. In addition to hourly data on the day of the test, data on daily 24-h averages of PM2.5, PM10, $\mathrm{NO}_{2}$, temperature and daily 10:00-18:00 h averages of $\mathrm{O}_{3}$ were obtained for the test date and each of the 60 days prior to FeNO testing in order to fully investigate the lag structure of the air pollution effects and the impact of temperature on the effects of air pollution. More details on the questionnaire information, collection of FeNO and air pollution data are provided in the supplementary data.

Race/ethnicity, physician diagnosis of asthma, history of respiratory allergy (allergic rhinitis and/or hayfever), asthma medication use during the previous 12 months and exposure to second-hand tobacco smoke (SHS) were based on parental reports. Height and weight were measured on the day of test. Age- and sex-specific percentiles based on the Centers for Disease Control and Prevention body mass index (BMI) growth charts (www.cdc.gov/NCCDPHP/dnpa/growthcharts/resources/sas. htm) were used to determine normal, overweight and obesity status of each child.

\section{Statistical analysis}

Descriptive and exploratory data analyses were conducted to: 1) examine the characteristics of the study population; 2) characterise the distribution of the FeNO measurements; and 3) assess the temporal trends of the air pollution levels during the study period. Multiple linear regression, with townspecific intercepts to control for any between community factors including those of regional differences in long-term pollution levels, was used to determine the relationship between levels of FeNO and variations in air pollution levels. A thorough model building process was conducted to examine the lag structure of air pollution effects, with adjustment for potential confounders and effect modifiers. These included age, sex, race/ethnicity, asthma, asthma medication use, history of respiratory allergy, time of FeNO collection, BMI percentiles, SHS, parental education, language of the questionnaire (English/Spanish), season, temperature (minimum, maximum and average levels on test date; and daily average levels for up to 30 days prior to the test), and whether FeNO testing was conducted outdoors. Seasonal effects were assessed by dividing the study period into the "cold" and "warm" seasons. The warm season was defined as March 16, 2005 to June 30, 2005 while the cold season was defined as the period from October 1, 2004 to March 15, 2005 based on Southern California climatic conditions.

Several types of lag-based models were considered, namely: 1) unconstrained lag models; 2) polynomial distributed lag models (PDL); 3) splines-based distributed lag models (SDLM); and 4) cumulative lag models. Linear, quadratic and cubic polynomials forms were considered for the PDL models with lags of up to 30 days prior to FeNO testing. Similarly, SDLM considered linear, quadratic and cubic splines with up to three knots chosen via a grid search over the 1-30-day lag period. Model selection was based on Akaike Information Criterion (AIC) since the models were not considered to be nested [16]. After choosing the final models for each pollutant, potential effect modification by sex, asthma, respiratory allergy and season were examined. Two pollutant models, guided by the correlation structure to avoid potential multi-collinearity, were fitted to examine co-dependency of the various pollutants. Sensitivity analysis on the lag structure was conducted using lagged effects of up to 60 days, whenever appropriate, to assess whether the air pollution effects extended beyond the 30-day lags. Similar analyses were also conducted on hourly lags for the $24 \mathrm{~h}$ prior to FeNO testing. Effects of long-term pollution levels were investigated as potential confounders or effect modifiers of the short-term effects in models that included random intercepts. All models were fitted to the SAS Version 9.1 statistical package (SAS Institute, Cary, NC, USA) and the R-statistical software. Statistical significance was assessed assuming a 0.05 significance level and a two-sided alternative hypothesis.

\section{RESULTS}

The study population was equally divided between boys and girls with the majority of the participants reporting their ethnicity as Hispanic (55.7\%) or non-Hispanic White $(34.0 \%)$ 
(table 1). FeNO levels were significantly higher in Asians, those filling in Spanish language questionnaires, children with asthma or respiratory allergy and those who came from households with less educated parents (less than high school), as reported previously [15]. Slight differences between the populations analysed here and previously [15] relate primarily to

\begin{tabular}{|c|c|c|c|c|}
\hline \multirow{2}{*}{$\begin{array}{l}\text { TABLE } 1 \\
\text { Variable }\end{array}$} & \multicolumn{4}{|c|}{$\begin{array}{l}\text { Characteristics of study population and } \\
\text { comparisons of exhaled nitric oxide fraction } \\
\text { (FeNO) levels }\end{array}$} \\
\hline & & Subjects ${ }^{\#}$ & Feno" & p-value ${ }^{+}$ \\
\hline \multicolumn{5}{|l|}{ Sex } \\
\hline Girls & & $1146(51.16)$ & $11.02 \pm 6.61$ & 0.53 \\
\hline Boys & & $1094(48.84)$ & $11.25 \pm 7.08$ & \\
\hline \multicolumn{5}{|l|}{ Age yrs } \\
\hline$<8$ & & 703 (31.38) & $10.8 \pm 6.59$ & 0.005 \\
\hline $8-9$ & & $1102(49.20)$ & $11.02 \pm 6.5$ & \\
\hline$>9$ & & 435 (19.42) & $12.18 \pm 8.28$ & \\
\hline \multicolumn{5}{|c|}{ Race/ethnicity } \\
\hline Non-Hispar & White & $828(37.01)$ & $10.28 \pm 5.96$ & $<0.0001$ \\
\hline Hispanic & & $1247(55.74)$ & $11.59 \pm 7.07$ & \\
\hline African-Am & ican & $61(2.73)$ & $11.82 \pm 8.28$ & \\
\hline Asian & & $86(3.84)$ & $14.15 \pm 11.04$ & \\
\hline Other & & $15(0.67)$ & $10.8 \pm 3.89$ & \\
\hline \multicolumn{5}{|l|}{ Asthma } \\
\hline Yes & & $169(7.54)$ & $13.87 \pm 10.41$ & $<0.0001$ \\
\hline No & & $2071(92.46)$ & $10.91 \pm 6.55$ & \\
\hline \multicolumn{5}{|c|}{ History of respiratory allergy } \\
\hline Yes & & $1167(52.10)$ & $11.94 \pm 8$ & $<0.0001$ \\
\hline No & & $1073(47.90)$ & $10.38 \pm 5.61$ & \\
\hline \multicolumn{5}{|c|}{ Questionnaire language } \\
\hline Spanish & & $531(23.71)$ & $12.3 \pm 7.51$ & $<0.0001$ \\
\hline English & & $1709(76.29)$ & $10.8 \pm 6.59$ & \\
\hline \multicolumn{5}{|c|}{ Body mass index } \\
\hline Underweig & $<5$ th percentile & $49(2.19)$ & $10.8 \pm 5.62$ & 0.85 \\
\hline Normal 5th & $<85$ th percentile & $1368(61.29)$ & $11.25 \pm 6.97$ & \\
\hline Overweight & 5 th to $<95$ th percentile & 395 (17.70) & $11.13 \pm 7.13$ & \\
\hline Obese $>9$ & percentile & $420(18.82)$ & $10.91 \pm 6.44$ & \\
\hline \multicolumn{5}{|c|}{ FeNO collected outside classroom } \\
\hline Yes & & $111(4.96)$ & $14.88 \pm 9.82$ & $<0.0001$ \\
\hline No & & $2129(95.04)$ & $11.02 \pm 6.72$ & \\
\hline \multicolumn{5}{|c|}{ Parental education } \\
\hline Less than $r$ & gh school & 424 (20.06) & $12.55 \pm 7.78$ & $<0.0001$ \\
\hline High schoc & & $390(18.45)$ & $11.13 \pm 7.24$ & \\
\hline Above high & school & $1300(61.49)$ & $10.8 \pm 6.48$ & \\
\hline \multicolumn{5}{|c|}{ Exposure to second-hand smoke } \\
\hline Yes & & $102(4.55)$ & $12.06 \pm 7.84$ & 0.20 \\
\hline No & & $2123(94.78)$ & $11.13 \pm 6.79$ & \\
\hline \multicolumn{5}{|c|}{$\begin{array}{l}\text { In utero exposure to maternal } \\
\text { smoking }\end{array}$} \\
\hline Yes & & $130(6.11)$ & $10.28 \pm 6.06$ & 0.11 \\
\hline No & & $1998(93.89)$ & $11.25 \pm 6.97$ & \\
\hline
\end{tabular}

Data are presented as $\mathrm{n}(\%)$ or mean $\pm \mathrm{SD}$, unless otherwise stated. ${ }^{*}$ : numbers do not always add up because of missing data; ': geometric mean and SD obtained from a univariate model testing equality of group means; ${ }^{+}$: tests for the equality of group means (did not include missing category). the availability of air pollution data. FeNO levels were not significantly associated with sex, BMI or exposures to tobacco smoke (in utero and second hand).

The time trends of daily 24-h average levels of PM2.5, PM10, $\mathrm{NO}_{2}$ and daily 10:00-18:00 $\mathrm{h}$ average levels of $\mathrm{O}_{3}$ during the study period (September 19, 2004 to June 22, 2005) are shown in figure 1 . The raw daily pollution data and the superimposed smooth plots show varying levels of seasonality among the time-series patterns of the ambient levels of the four air pollutants. Table 2 presents the correlation structure between the four pollutants of interest which were calculated using 24-h averages over a 30-day lag before each subject's FeNO measurement, except ozone, which used averages of 10:0018:00 $\mathrm{h} \mathrm{O}_{3}$ concentrations over a 30-day lag prior to FeNO testing. The correlations are shown for warm and cold seasons because we observed differences in the cold and warm seasons. PM10 and PM2.5 were highly positively correlated in both seasons. $\mathrm{O}_{3}$ and $\mathrm{NO}_{2}$ were negatively correlated in the cold season. $\mathrm{O}_{3}$ was positively correlated with PM10 and PM2.5 in the warm season, but was virtually uncorrelated with the particulate matter pollutants during the cold season.

Based on the AIC [16], we chose the best model for each pollutant among polynomial/spline distributed lag models (linear, quadratic or cubic) and cumulative lagged average models with lags up to 30 days prior to FeNO tests. We found that $8,7,6$ and 23 cumulative lagged-daily average levels were the best models for PM2.5, PM10, $\mathrm{NO}_{2}$ and $\mathrm{O}_{3}$, respectively. Figure 2 shows the lag structure over a 30-day period of the cumulative averaged air pollution effects from fully adjusted multiple linear regression models. In addition to the pollutant under consideration, the final models adjusted for community, race/ethnicity, sex, asthma, asthma medication use, history of respiratory allergy, age, time of FeNO collection, BMI, SHS, parental education, language of the questionnaire (English/ Spanish), season and whether FeNO testing was conducted outdoors. The results from these final models assessing the effects of air pollution on FeNO are presented in table 3 and corresponding partial regression plots depicting the regression lines along with scatter plots of the residuals are presented in the supplementary data (fig. E1). We found that short-term levels of PM2.5, PM10 and $\mathrm{O}_{3}$ were significantly associated with airway inflammation. Note that these results are interpreted as within-community effects of the air pollution metrics on FeNO because the models included community-specific intercepts [17]. Daily 24-h average PM2.5 concentration (1-8 day lagged cumulative average) was significantly associated with $17.42 \%$ $(p<0.01)$ higher levels of FeNO over the interquartile range (IQR) of $7.5 \mu \mathrm{g} \cdot \mathrm{m}^{-3}$. Daily 24-h average PM10 concentration accumulated over 1-7 day lags was significantly associated $(\mathrm{p}<0.05)$ with $9.25 \%$ higher FeNO levels per the IQR of $12.97 \mu \mathrm{g} \cdot \mathrm{m}^{-3}$. Similarly, 10:00-18:00 $\mathrm{h}$ cumulative average $\mathrm{O}_{3}$ (over 1-23 lag days) concentrations prior to FeNO testing was significantly associated with $14.25 \%$ higher FeNO levels over the IQR of $15.42 \mathrm{ppb}(\mathrm{p}<0.01)$. There was no statistically significant association with $\mathrm{NO}_{2}$ (best model selected for 1-6 day lag average), even though tendency towards positive association was observed as in the other three pollutants. There was no significant effect of long-term pollution for any of the four pollutants under consideration (not shown). 

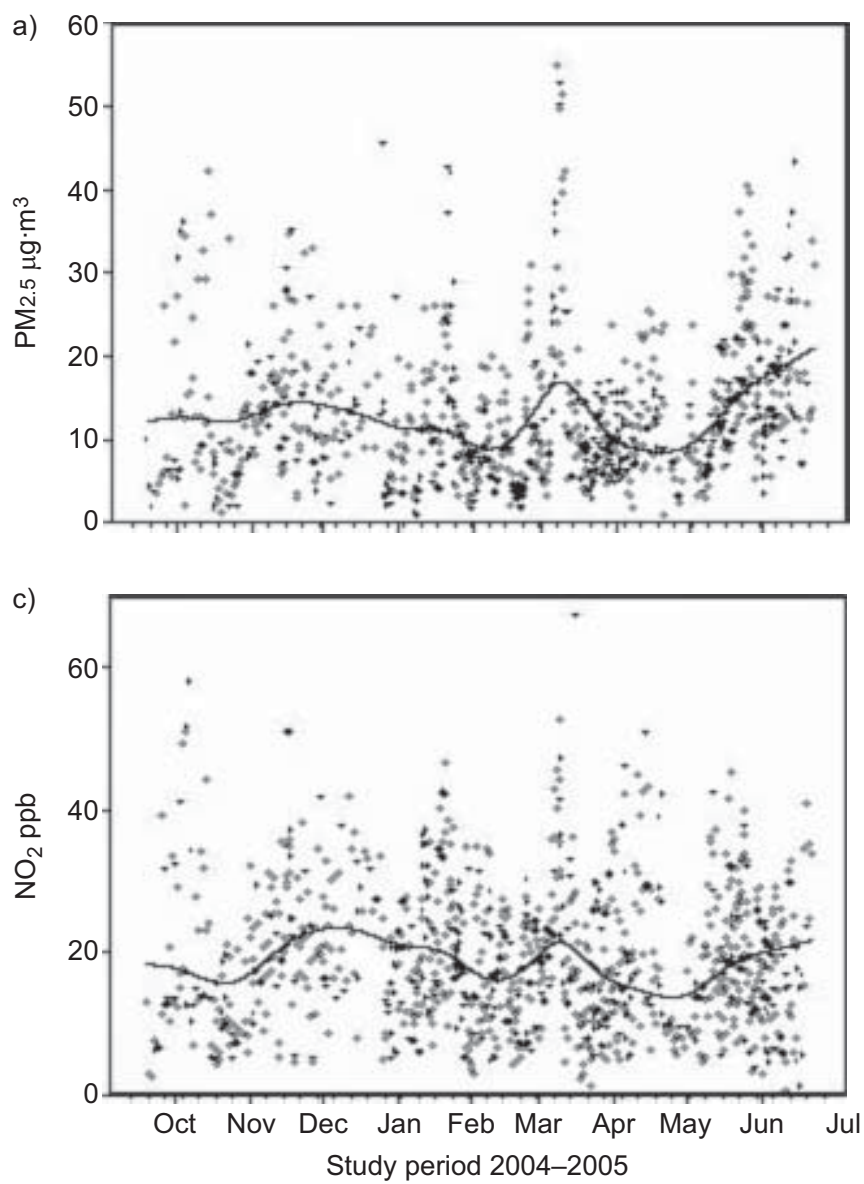
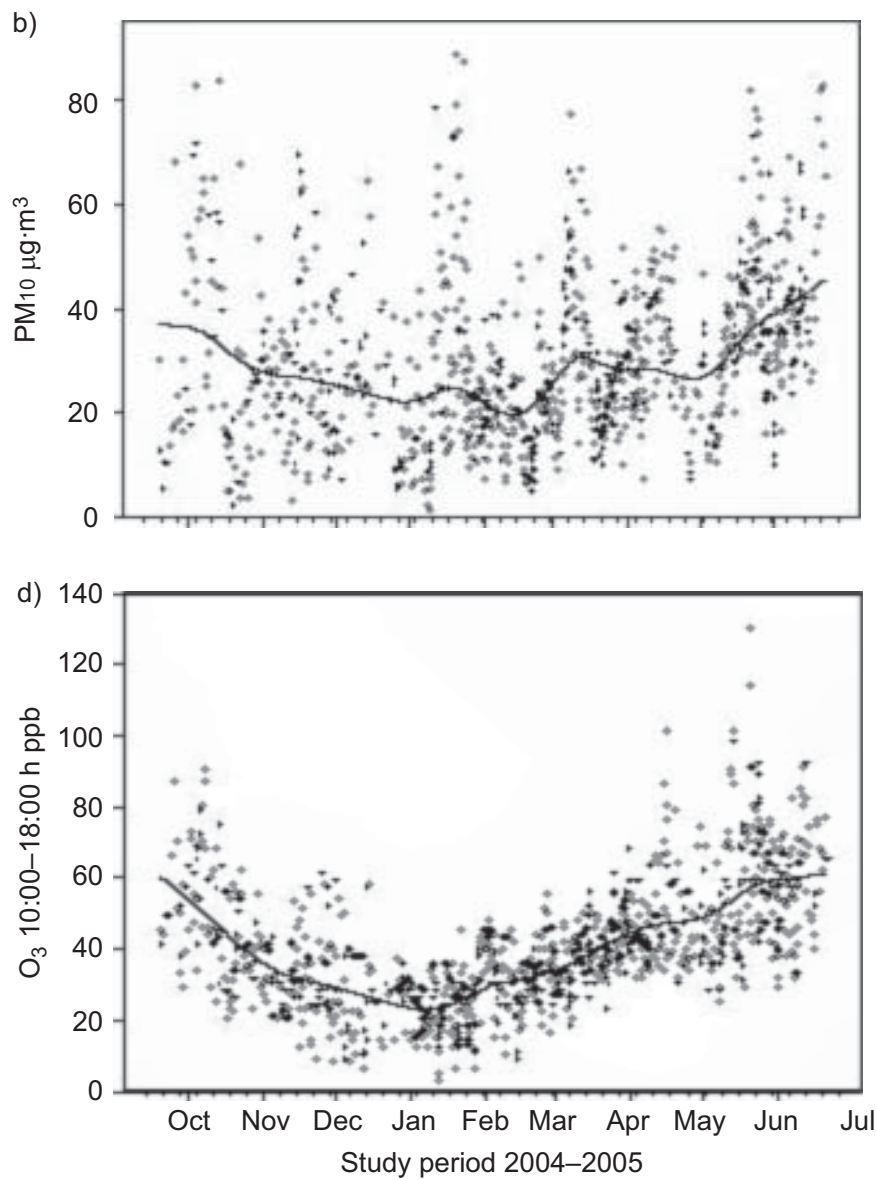

FIGURE 1. The time trends of daily $24-\mathrm{h}$ average levels of a) particles with a $50 \%$ cut-off aerodynamic diameter of $2.5 \mu \mathrm{m}$ (PM2.5), b) particles with a $50 \%$ cut-off aerodynamic diameter of $10 \mu \mathrm{m}$ (PM10), c) $\mathrm{NO}_{2}$ and d) daily 10:00-18:00 $\mathrm{h}$ average levels of $\mathrm{O}_{3}$ during the study period (September 19, 2004 to June 22, 2005). The superimposed smooth plot depicts the overall temporal trend and is based on a smooth spline function with 10 degrees of freedom.

The effects of the air pollutants did not significantly vary by sex, asthma or respiratory allergy status (table 4). In seasonspecific models, PM10, PM2.5 and $\mathrm{O}_{3}$ had relatively larger effects in the warm season, but this seasonal difference was

\begin{tabular}{|c|c|c|c|c|}
\hline Pollutants & PM2.5 & PM10 & $\mathrm{NO}_{2}$ & $\mathrm{O}_{3}$ \\
\hline PM2.5 & & 0.79 & 0.47 & 0.61 \\
\hline PM10 & 0.72 & & 0.49 & 0.59 \\
\hline $\mathrm{NO}_{2}$ & 0.65 & 0.55 & & 0.15 \\
\hline $\mathrm{O}_{3}$ & -0.05 & 0.06 & -0.4 & \\
\hline
\end{tabular}

PM2.5: particles with a $50 \%$ cut-off aerodynamic diameter of $2.5 \mu \mathrm{m}$; PM10: particles with a $50 \%$ cut-off aerodynamic diameter of $10 \mu \mathrm{m}$. \#: Pearson correlation coefficients ( $r$ ) between any two pollutants. The data in bold represents correlations during the warm season (March 16, 2005 to June 30, 2005), whereas the un-bolded data shows correlations in the cold season (October 1, 2004 to March 15, 2005). ": correlations are estimated using 24-h averages over a 30-day lag before each subject's exhaled nitric oxide fraction (FeNO) measurement except ozone, which used averages of 10:00-18:00 h ozone concentrations over a 30-day lag prior to FeNO testing. statistically significant for PM10 only $(19.9 \%$ versus $4.3 \%$ per IQR of $12.97 \mu \mathrm{g} \cdot \mathrm{m}^{-3}$; interaction $\left.\mathrm{p}=0.02\right)$. Although the seasonal differences were not statistically significant, the effects of PM2.5 and $\mathrm{O}_{3}$ were also higher in the warm season. In two pollutant models that allowed for co-adjustment of each particulate matter measure with $\mathrm{O}_{3}$, the significant effects of PM2.5 and PM10 were found to be robust to adjustments for effects of $\mathrm{O}_{3}$ (not shown).

Several models were fitted to further test the sensitivity of the results to various alternative model specifications. Extending the number of lagged days to 60 days did not alter the final model choices (data not shown). A similar investigation on the hourly lagged effects for the $24 \mathrm{~h}$ prior to FeNO testing, based on full considerations for distributed lagged structures, did not reveal any significant findings for any of the pollutants (data not shown). In sensitivity analyses, we found that the pollutant effects were not confounded by levels of temperature (maximum, minimum and average levels) on the day of the test or cumulative 6-day lagged average temperature level (fitted only when there were no issues with multi-collinearity), selected based on a model search similar to that performed for air pollutants (data not shown). The effects of the air pollutants did not significantly vary by long-term pollution levels (dividing the communities into high/low categories at the 

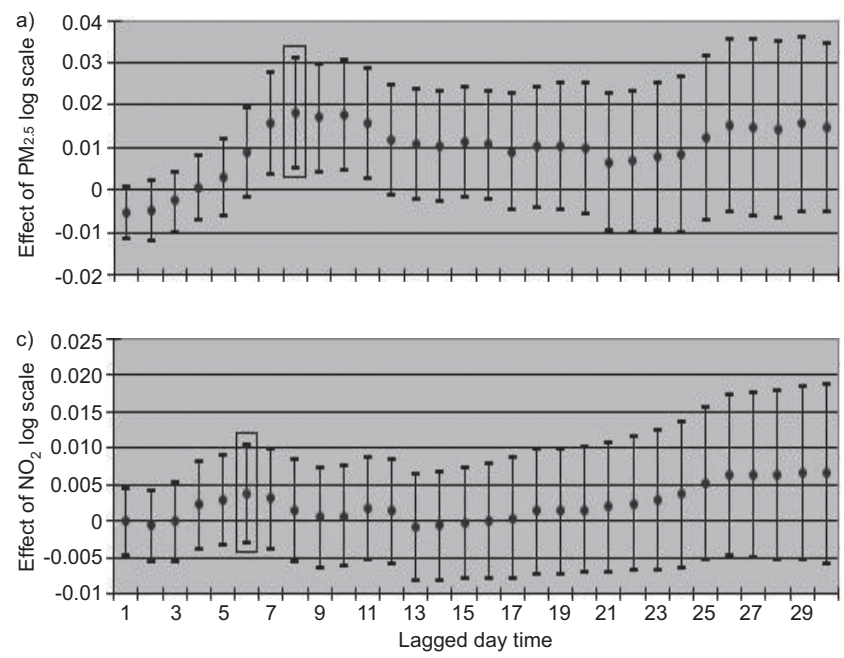
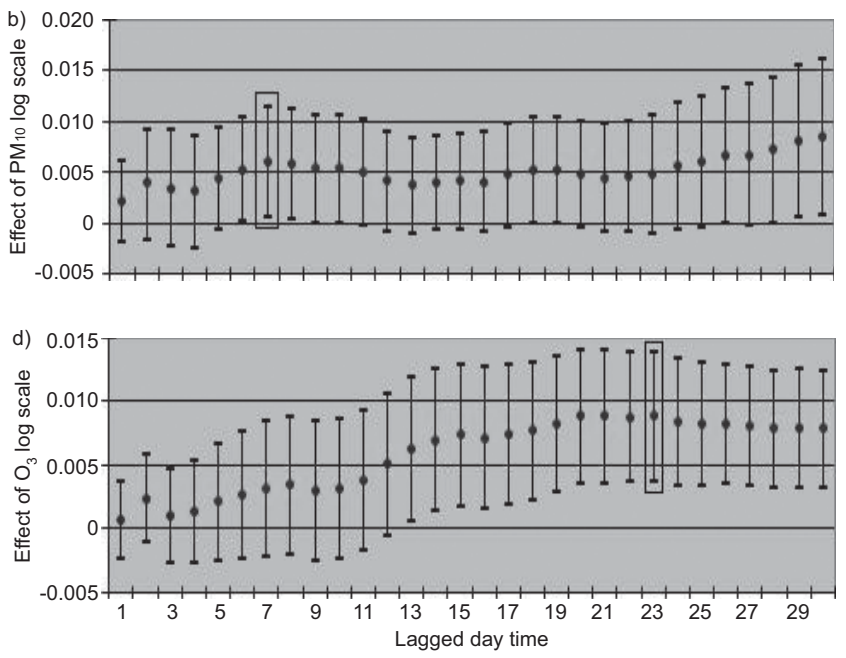

FIGURE 2. Lag structure over a 30-day period of the cumulative averaged air pollution effects from fully adjusted multiple linear regression models for daily 24-h average levels of a) particles with a 50\% cut-off aerodynamic diameter of $2.5 \mu \mathrm{m}(\mathrm{PM} 2.5)$, b) particles with a $50 \%$ cut-off aerodynamic diameter of $10 \mu \mathrm{m}\left(\mathrm{PM}_{10}\right)$, c) $\mathrm{NO}_{2}$ and d) daily 10:00-18:00 h average levels of $\mathrm{O}_{3}$. The $\mathrm{y}$-axis represents the adjusted effect estimate of each pollutant on natural log transformed exhaled nitric oxide fraction. The best lag for each pollutant, selected via Akaike Information Criterion, is indicated by the rectangular box in each panel.

median) or by use of non-inhaled corticosteroid medication (data not shown). Sensitivity analysis conducted to test for finer temporal influences by including terms for months, instead of season, did not give better model performance. Hence, we used the more parsimonious model of adjusting for season in our final models.

\section{DISCUSSION}

We have shown that short-term increases in ambient air pollution are associated with higher levels of FeNO in children, independent of asthma and allergy status. We found that the association with the particulate matter metrics was the strongest, significantly stronger in the warm season for PM10 and robust to adjustments for effects of other pollutants. Our

\section{TABLE 3 Results of cumulative daily average lagged air pollutant effect on exhaled nitric oxide fraction $(\mathrm{FeNO})^{\#}$}

\begin{tabular}{lcc} 
Pollutant & Lag structure & FeNO $^{+}$ \\
\hline PM2.5 & 1-8 day average & $17.42(6.15-29.89)^{\star *}$ \\
$\mathbf{P M}_{10}$ & $1-7$ day average & $9.25(1.58-17.50)^{*}$ \\
$\mathbf{N O}_{2}$ & $1-6$ day average & $5.13(-2.34-13.17)$ \\
$\mathbf{O}_{3}$ & $1-23$ day average & $14.25(5.24-24.04)^{\star *}$ \\
\hline
\end{tabular}

Data are presented as \% difference (95\% CI). PM2.5: particles with a 50\% cut-off aerodynamic diameter of $2.5 \mu \mathrm{m}$; PM10: particles with a $50 \%$ cut-off aerodynamic diameter of $10 \mu \mathrm{m}$. ${ }^{\#}$ : all models are adjusted for community, race/ethnicity, sex, asthma, asthma medication use, history of respiratory allergy, age, time of $F$ eNO collection, body mass index, second-hand smoke, parent education, language of the questionnaire (English/Spanish), season and whether FeNO testing was conducted outdoors. ": all pollutants are 24-h average, except for ozone (10:00-18:00 $\mathrm{h}$ average). ${ }^{+}$: results are scaled to the interquartile range values of $7.5 \mu \mathrm{g} \cdot \mathrm{m}^{-3}(\mathrm{PM} 2.5), 12.97 \mu \mathrm{g} \cdot \mathrm{m}^{-3}$ (PM10), $10.62 \mathrm{ppb}\left(\mathrm{NO}_{2}\right)$ and $15.42 \mathrm{ppb}\left(\mathrm{O}_{3}\right)$. **: $\mathrm{p}<0.01 ; *$ : $\mathrm{p}<0.05$. data also showed that the effects for PM2.5 and PM10 had relatively shorter lag structures compared to those for $\mathrm{O}_{3}$ that had a longer lag structure of 23 days prior to FeNO measurement.

In this study, our main aim was to evaluate the impact of ambient air pollutants without subjecting the analysis to any $a$ priori lags, as no study to our knowledge evaluated these associations in such a manner. We found significant positive associations of PM2.5, PM10, $\mathrm{O}_{3}$ and FeNO using larger lags. Our findings are generally consistent with earlier reports [18-26] although we observed longer lagged-effects of ambient air pollutants.

In contrast to other studies conducted in children [18, 21], we did not find significant effects on the shorter hourly time scale during the $24 \mathrm{~h}$ prior to FeNO testing. This may be due, in part, to adjustment of ambient NO in our study. From our earlier work which studied the relationship between online and offline FeNO data [14], we reported that association of offline FeNO with ambient NO is likely, in part, to be an artefact from intrusion of high ambient NO concentrations into the offline collection devices and bags [18, 21].

Although there are differences in findings across studies in terms of lagged effects of ambient air pollutants on FeNO in children, there are biologically plausible reasons for such inconsistencies. The differences in findings may reflect differences in levels of exposures with varying degree of correlations among pollutants across geographical regions and seasons [18, $22,27]$, testing the hypothesis among susceptible subjects (children with asthma or allergy) [23-27] or assessment in very high exposure environments [20]. For example, exposure to high $\mathrm{O}_{3}$ concentrations during two summer camp days ( $8 \mathrm{~h}$ average $\geqslant 135 \mu \mathrm{g} \cdot \mathrm{m}^{-3}$ ) resulted in a significant increase in FeNO in evenings among healthy children [20]. In another study, DELFINO et al. [18] found 2-day moving average of personal PM2.5 was associated with higher FeNO in children with persistent asthma. These findings suggest that association 


\begin{tabular}{|c|c|c|c|c|}
\hline No & $18.8(7.3-31.5)^{\star *}$ & $9.6(1.9-17.9)^{*}$ & $5.9(-1.7-14.1)$ & $14.5(5.3-24.4)^{\star *}$ \\
\hline Yes & $5.8(-9.1-23.2)$ & $2.1(-11.4-17.5)$ & $-3.6(-17.7-12.7)$ & $12.6(-0.7-27.7)^{5}$ \\
\hline No & $13.9(1.9-27.4)^{*}$ & $7.1(-1.4-16.4)$ & $4.7(-1.9-11.7)$ & $12.4(2.7-23.0)^{*}$ \\
\hline Yes & $19.6(7.7-32.9)^{\star \star}$ & $10.8(2.5-19.9)^{*}$ & $7.8(1.4-14.7)^{\star}$ & $15.4(6.0-25.7)^{\star \star}$ \\
\hline p-interaction & 0.22 & 0.32 & 0.31 & 0.40 \\
\hline \multicolumn{5}{|l|}{ Season } \\
\hline Warm & $18.4(6.8-31.4)^{\star \star}$ & $19.9(7.9-33.2)^{\star \star}$ & $4.8(-5.0-15.6)$ & $15.3(5.3-26.2)^{\star *}$ \\
\hline Cold & $13.0(-2.6-31.0)$ & $4.3(-3.9-13.2)$ & $5.4(-3.4-15.0)$ & $10.2(-7.5-31.3)$ \\
\hline
\end{tabular}

Data are presented as \% difference $(95 \% \mathrm{Cl})$, unless otherwise stated. PM2.5: particles with a 50\% cut-off aerodynamic diameter of $2.5 \mu \mathrm{m}$; PM10: particles with a $50 \%$ cutoff aerodynamic diameter of $10 \mu \mathrm{m} . *$ : all pollutants are 24-h average, except for ozone (10:00-18:00 h average); ": all models are adjusted for community, race/ethnicity, sex, asthma, asthma medication use, history of respiratory allergy, age, time of FeNO collection, body mass index, second-hand smoke, parent education, language of the questionnaire (English/Spanish), season and whether FeNO testing was conducted outdoors. In addition, stratum specific effects of pollution are reported for each modifying factor (asthma, history of respiratory allergy or season) by including interaction terms wherever appropriate. ${ }^{+}$: results are scaled to the interquartile range values of $7.5 \mu \mathrm{g} \cdot \mathrm{m}^{-3}$ (PM2.5), $12.97 \mu \mathrm{g} \cdot \mathrm{m}^{-3}$ (PM10), $10.62 \mathrm{ppb}\left(\mathrm{NO}_{2}\right)$ and $15.42 \mathrm{ppb}\left(\mathrm{O}_{3}\right){ }^{{ }^{\varsigma}}{ }^{\text {s: }} \mathrm{p}<0.1 ; *: \mathrm{p}<0.05 ; * *: \mathrm{p}<0.01$

between ambient air pollutants and FeNO may depend on level of exposure and individual susceptibility to the inflammatory effects of air pollutants.

We did not find significant influence of a number of potential susceptibility factors (i.e. asthma and allergy) on the associations between ambient air pollutants and FeNO suggesting that current levels of ambient pollutants have the potential to increase nitrosative stress in both healthy and susceptible children. While similar effects of air pollution on FeNO in atopic and non-atopic adults have been reported previously [28], our results are also in contrast to findings from other studies. For example, BARRAZA-VILLAREAL et al. [22] report significant effects of 8-h cumulative averages of $\mathrm{PM} 2.5$ and $\mathrm{O}_{3}$ on FeNO levels among asthmatics. However, there did not appear to be significant differences with effects in nonasthmatics, which were nonsignificant due to a small sample size $(n=50)$. In our study, we did not find significant effects for any of the pollutants in the $24 \mathrm{~h}$ prior to FeNO testing even when we only considered children with asthma (data not shown). We found a significant heterogeneity of effects of PM10 on FeNO by season in Southern California, and this heterogeneity did not seem to be explained by weather as characterised by temperature. Although the magnitude of correlation between PM10 and PM2.5 and $\mathrm{NO}_{2}$ were comparable between seasons, the correlation between PM10 and $\mathrm{O}_{3}$ were strikingly different. The positive association between PM10 and FeNO in summer remained robust even after adjusting for $\mathrm{O}_{3}$. Further research is needed to evaluate whether compositional difference exists in PM10 by seasons that could account for the observed differential effects.

The advantages of the current study include: 1) evaluation of the air pollution effects on FeNO using a large, ethnically diverse population of children; 2) substantial range in exposures to the spectrum of complex multi-pollutant mixtures available in the
Southern California region which could represent the full national range; 3 ) a thorough investigation on the lag structure of up to 60 days prior to FeNO testing; 4) determination of independent effects of pollutants in a multi-pollutant setting; and 5) testing whether the associations varied by susceptibility factors (asthma and allergy) and by season.

There are some concerns in the scientific community regarding use of FeNO as a marker of airway inflammation [29, 30]. However, our data, along with a large body of evidence from earlier work, indicates that $F$ eNO is influenced significantly by ambient air pollution and is correlated with atopic conditions (asthma, allergy, sputum or blood eosinophil and airway hyperresponsiveness), although such correlation is often not strong. Therefore, it can be argued that FeNO reflects air pollution responsive domains of airway inflammation and more research is needed to understand its correlates.

The results from our study should be interpreted in light of some limitations. The cross sectional nature of the analysis precludes from adequately assessing the independent effects of short-term fluctuations of air pollution on FeNO, after adjustments for long-term regional effects of air pollution. Our FeNO data was based on "online" predictions from an offline measure. While this process might potentially introduce misclassification and measurement error, there was a very strong correlation between the two measures (model $\mathrm{r}^{2}=0.94$ ) [14]. The main study findings were essentially identical when the offline FeNO values were used in our final models. There is potential for misclassification of exposure assignments because we do not have information on time-activity patterns for the study subjects for the duration of the lags evaluated in the study; however, the regional nature of particulate matter and $\mathrm{O}_{3}$ reduces the potential misclassification. Further research is warranted that incorporates time-activity pattern to improve exposure assignment. 
Our air pollution measures were obtained from central site monitors placed in each of our study communities. To minimise the confounding of location and seasonal effects, each community was visited at least twice in different seasons. However, there is still potential for residual spatio-temporal confounding since the study design and budgetary/logistical limitations did not allow measurement of FeNO levels in all communities across the entire study period. To the extent possible, our models included seasonal and other temporal factors as adjustment factors and season-specific models were considered. Controlling for temporal effects using month specific factors and/or smooth functions of time did not result in better model fit compared to those adjusted for season in our final models. Missing days of exposure and interpolation of air pollution data to fill in data gaps with modelled predictions using data from nearby monitors are potential sources of bias. However, sensitivity analyses that limited use to complete data did not alter the main study findings (data not shown).

Our ability to thoroughly assess the effects of use of asthma and allergy medication is limited. We used parent-reported questionnaire based information to collect information on history of respiratory allergy, physician diagnosis of asthma, and medication use for asthma in order to assess the effects of these important factors on confounding and/or modifying the association between air pollution and FeNO. Our findings are internally consistent showing higher FeNO among children with asthma or respiratory allergy.

In conclusion, our data showed that current levels of ambient air pollutants (often meeting regulatory standards) are associated with increased FeNO in children with and without asthma. Because FeNO measurement allows evaluation of airway inflammation noninvasively, use of this biomarker is useful in population-based epidemiological research in assessing the impact of ambient air pollutants on nitrosative stress in airways. We recently reported that elevated FeNO is associated with increased risk of new onset asthma [31], a finding supported by a recent study that found FeNO could predict wheeze onset in adults [11]. Further research is warranted to examine whether FeNO could predict asthma/ wheeze incidence in children exposed to different levels of ambient air pollution. If such association exists, then measurement of FeNO could be used as a useful intermediate marker to detect susceptible children who are at high risk of adverse respiratory health outcomes from air pollution.

\section{SUPPORT STATEMENT}

This work was supported by the National Heart, Lung and Blood Institute (grants 5R01HL61768 and 5R01HL76647), the Southern California Environmental Health Sciences Center (grant 5P30ES007048) funded by the National Institute of Environmental Health Sciences, the Children's Environmental Health Center (grants 5P01ES009581, R826708-01 and RD831861-01) funded by the National Institute of Environmental Health Sciences and the Environmental Protection Agency, the National Institute of Environmental Health Sciences (grant 5P01ES011627), and the Hastings Foundation.

\section{STATEMENT OF INTEREST}

A statement of interest for F. Lurman can be found at www.erj. ersjournals.com/site/misc/statements.xhtml

\section{ACKNOWLEDGEMENTS}

We are indebted to the school principals, teachers, students and parents in each of the 13 study communities for their cooperation and especially to the members of the health testing field team for their efforts.

\section{REFERENCES}

1 Gauderman WJ, Avol E, Gilliland F, et al. The effect of air pollution on lung development from 10 to 18 years of age. $N$ Engl J Med. 2004; 351: 1057-1067.

2 Gauderman WJ, Vora H, McConnell R, et al. Effect of exposure to traffic on lung development from 10 to 18 years of age: a cohort study. Lancet 2007; 369: 571-577.

3 McConnell R, Berhane K, Gilliland F, et al. Air pollution and bronchitic symptoms in Southern California children with asthma. Environ Health Perspect 1999; 107: 757-760.

4 McConnell R, Berhane K, Gilliland FD, et al. Sports and asthma in children exposed to ozone. Am J Respir Crit Care Med 2001; 163: Suppl. 5, A174.

5 McConnell R, Berhane K, Gilliland FD, et al. Prospective study of air pollution and bronchitic symptoms in children with asthma. Am J Respir Crit Care Med 2003; 168: 790-797.

6 McConnell R, Berhane K, Gilliland F, et al. Asthma in exercising children exposed to ozone: a cohort study. Lancet 2002; 359: 386-391.

7 McConnell R, Berhane K, Yao L, et al. Traffic, susceptibility, and childhood asthma. Environ Health Perspect 2006; 114: 766-772.

8 Recommendations for standardized procedures for the on-line and off-line measurement of exhaled lower respiratory nitric oxide and nasal nitric oxide in adults and children-1999. This official statement of the American Thoracic Society was adopted by the ATS Board of Directors, July 1999. Am J Respir Crit Care Med 1999; 160: 2104-2117.

9 American Thoracic Society/European Respiratory Society. ATS/ ERS recommendations for standardized procedures for the online and offline measurement of exhaled lower respiratory nitric oxide and nasal nitric oxide, 2005. Am J Respir Crit Care Med. 2005; 171: 912-930.

10 Kharitonov S, Barnes P. Exhaled biomarkers. Chest 2006; 130 1541-1546.

11 Olin AC, Rosengren A, Thelle DS, et al. Increased fraction of exhaled nitric oxide predicts new-onset wheeze in a general population. Am J Respir Crit Care Med 2010; 181: 324-327.

12 Peters JM, Avol E, Navidi W, et al. A study of twelve Southern California communities with differing levels and types of air pollution. I. Prevalence of respiratory morbidity. Am J Respir Crit Care Med 1999; 159: 760-767.

13 Peters JM, Avol E, Gauderman WJ, et al. A study of twelve Southern California communities with differing levels and types of air pollution. II. Effects on pulmonary function. Am J Respir Crit Care Med 1999; 159: 768-775.

14 Linn WS, Berhane KT, Rappaport EB, et al. Relationships of online exhaled, offline exhaled, and ambient nitric oxide in an epidemiologic survey of schoolchildren. J Expo Sci Environ Epidemiol 2009; 19: 674-681.

15 Linn WS, Rappaport EB, Berhane KT, et al. Exhaled nitric oxide in a population-based study of southern California schoolchildren. Respir Res 2009; 10: 28.

16 Akaike H. Information theory and an extension of the maximum likelihood principle. In: Petrov BN, Csaki F, eds. 2nd International Symposium on Information Theory. Budapest, Akademia Kiado, 1973; pp. 267-281.

17 Berhane K, Gauderman W, Stram D, et al. Statistical issues in studies of the long term effects of air pollution: The Southern California Children's Health Study. Stat Sci 2004; 19: 414-449. 
18 Delfino RJ, Staimer N, Gillen D, et al. Personal and ambient air pollution is associated with increased exhaled nitric oxide in children with asthma. Environ Health Perspect 2006; 114: 1736-1743.

19 Flamant-Hulin M, Caillaud D, Sacco P, et al. Air pollution and increased levels of fractional exhaled nitric oxide in children with no history of airway damage. J Toxicol Environ Health A 2010; 73: 272-283.

20 Nickmilder M, Carbonnelle S, de Burbure C, et al. Relationship between ambient ozone and exhaled nitric oxide in children. JAMA 2003; 290: 2546-2547.

21 Fischer PH, Steerenberg PA, Snelder JD, et al. Association between exhaled nitric oxide, ambient air pollution and respiratory health in school children. Int Arch Occup Environ Health 2002; 75: 348-353.

22 Barraza-Villarreal A, Sunyer J, Hernandez-Cadena L, et al. Air pollution, airway inflammation, and lung function in a cohort study of Mexico City schoolchildren. Environ Health Perspect 2008; 116: 832-838.

23 Renzetti G, Silvestre G, D'Amario C, et al. Less air pollution leads to rapid reduction of airway inflammation and improved airway function in asthmatic children. Pediatrics 2009; 123: 1051-1058.

24 Allen RW, Mar T, Koenig J, et al. Changes in lung function and airway inflammation among asthmatic children residing in a woodsmoke-impacted urban area. Inhal Toxicol 2008; 20: 423-433.

25 Koenig JQ, Mar TF, Allen RW, et al. Pulmonary effects of indoorand outdoor-generated particles in children with asthma. Environ Health Perspect 2005; 113: 499-503.

26 Mar TF, Jansen K, Shepherd K, et al. Exhaled nitric oxide in children with asthma and short-term PM2.5 exposure in Seattle. Environ Health Perspect 2005; 113: 1791-1794.

27 Liu L, Poon R, Chen L, et al. Acute effects of air pollution on pulmonary function, airway inflammation, and oxidative stress in asthmatic children. Environ Health Perspect 2009; 117: 668-674.

28 van Amsterdam JG, Hollander A, Snelder JD, et al. The effect of air pollution on exhaled nitric oxide of atopic and nonatopic subjects. Nitric Oxide 1999; 3: 492-495.

29 Taylor D, Pijnenburg M, Smith A, et al. Exhaled nitric oxide measurements: Clinical application and interpretation. Thorax 2006; 61: 817-827.

30 Fleming L, Wilson N, Bush A. No the evidence: what have measurements of exhaled nitric oxide got to offer? J Pediatr 2006; 149: 156-158.

31 Bastain TM, Islam T, Berhane KT, et al. Exhaled nitric oxide, susceptibility and new-onset asthma in the children's health study. Eur Respir J 2010; 37: 523-531. 